\title{
A CONSTRUÇÃO E A VALIDAÇÃO DE UMA ESCALA PARA MENSURAR O EFEITO MANADA DENTRO DE RESTAURANTES E SIMILARES
}

\author{
CONSTRUCTION AND VALIDATION OF A SCALE TO MEASURE THE HERD EFFECT WITHIN \\ RESTAURANTS AND SIMILAR
}

\section{Rodrigo Souza Canto}

rodrigoscanto@hotmail.com

Mestrado Profissional em Gestão de Alimentos e Bebidas /Universidade Anhembi Morumbi - São Paulo/SP,

Brasil

ORCID: https://orcid.org/0000-0002-3642-8039

\section{Sérgio Luis Ignácio de Oliveira}

slmarketing@uol.com.br

Mestrado Profissional em Gestão de Alimentos e Bebidas /Universidade Anhembi Morumbi - São Paulo/SP, Brasil

ORCID: https://orcid.org/0000-0001-6223-1515

\section{Resumo}

Este estudo buscou desenvolver uma escala para mensurar o comportamento de manada em restaurantes. Como fundamentação teórica procurou evidenciar a tendência, em algumas decisões de compra, de um grupo de consumidores influenciar a escolha de outros. Na verificação dos resultados foi utilizada a análise fatorial exploratória. A amostra foi validade pelos testes de KMO e Bartllet. A análise foi realizada pelo método Componentes principais e a rotação pelo Varimax. O fator Alpha de Cronbach assegurou a confiabilidade da pesquisa. O tratamento estatístico agrupou os fatores em três constructos: "Conforto Cognitivo", "Heurística e "Conformidade Social", validando, desta forma, o instrumento proposto.

Palavras-chave: Setor de Alimentos e Bebidas. Comportamento de Manada. Processo Decisório de Compra.

\begin{abstract}
This study aimed to develop a scale to measure herd behavior in restaurants. As a theoretical foundation it sought to highlight the tendency, in some purchasing decisions, of a group of consumers to influence the choice of others. In the verification of the results the exploratory factor analysis was used. The sample was valid by the KMO and Bartllet tests. The analysis was performed by the Principal Components method and rotation by Varimax. Cronbach's alpha factor ensured the reliability of the research. The statistical treatment grouped the factors in three constructs: "Cognitive Comfort", "Heuristic and "Social Compliance", thus validating the proposed instrument.
\end{abstract}

Keywords: Food and Beverages industry. Herd Behavior. Decision Making Process. 


\section{Introdução}

O Setor de alimentos e Bebidas (A\&B) é um pilar importante dentro da economia nacional. Segundo a ABIA (2017) representa cerca de 10.1\% do Produto Interno Bruto (PIB), e fechou 2016 com um faturamento na ordem de $\mathrm{R} \$ 614,3$ bilhões e empregando mais de 1,6 milhões de pessoas. As exportações mantiveram crescimento em 2016 com US $\$ 36,4$ bilhões contra US $\$ 35,2$ bilhões registrados em 2015. A sua participação na balança comercial brasileira foi significativa, em 2016, contribuiu com saldo de US\$ 31,5 bilhões para o superávit total da balança comercial que foi de US\$ 47,7 bilhões. Também deve-se destacar a alimentação fora do lar um conjunto de instituição que fazem parte do macro setor de $\mathrm{A} \& \mathrm{~B}$, no qual os restaurantes, alvo do estudo, estão contemplados. A mudança no estilo de vida da população e melhoria da renda familiar influenciam diretamente nos hábitos alimentares, conduzindo um consumo mais frequente em restaurantes, shoppings centers, eventos, entre outros. Estima-se um crescimento anual de 14,2\% nesse setor. $\mathrm{Na}$ média $31 \%$ do orçamento doméstico com alimentação é gasto com alimentação fora do lar (ABRASEL, 2015; ABIA 2017).

Ciente da importância do setor de $\mathrm{A} \& \mathrm{~B}$ e a compreensão da importância em entender os agentes e consumidores presentes no setor, destaca-se, neste cenário, que a tendência de comportamentos semelhantes sugere algum tipo de irracionalidade, uma motivação psicológica induzida por uma lealdade em estar de acordo com os membros do grupo. Um indivíduo parece contagiado pelo outro, e age de forma inconsciente, o denominado Comportamento Manada. Modelos têm como ideia central o fato de que as pessoas adquirem informações para a tomada de decisão observando ações de outras, como o "modelo de cascata informacional" de Banerjee (1992).

Pelo viés do Marketing, esse comportamento pode ser notado nas teorias de comportamento do consumidor como os trabalhos de Cobra (1992), Kotler e Keller (2012), Limeira (2009), Oliveira (2007), Rocha (2015), Solomon (2009), entre outros que tratam do comportamento de compra e consumo, e destacam tais fatores quando abordam as influencias sociais no processo de compra, no qual um indivíduo parece ser contagiado pelo outro e muitas vezes age de maneira não consciente em seus processos de escolha.

Esse comportamento parece ser relevante em momentos de incerteza; quando há um excesso de informações; limitações de tempo e processamento de informação que dificultam a escolha do consumidor. Desse modo, esse trabalho abordou fatores determinantes a este comportamento. Criouse um mapa teórico com fatores relacionados ao Herd Behavior - Comportamento de Manada. Uma métrica que explica os principais fatores: experiências repetidas, bom humor, heurística, crowdness, redução de incerteza, aprendizado, reputação e desindividualização.

A pesquisa encontrou, na literatura nacional e estrangeira, poucos trabalhos, e nenhuma escala, o que levou a construção deste instrumento para o melhor entendimento deste fenômeno. E, devido a crescente busca por parte de acadêmicos e do mercado em entender comportamentos não conscientes dos consumidores, e a constatação desta lacuna no setor de A\&B motivou o presente estudo e conduziu à questão central da pesquisa: Como é possivel medir o comportamento de manada dentro de restaurantes e similares? Em vista do problema identificado, chegou-se ao seguinte objetivo geral: construir e validar uma escala para medir o comportamento de manada dentro de estabelecimentos de alimentação, mais particularmente restaurantes, lanchonetes, confeitarias, dentre outros. Como objetivos específicos: a) Compreender as principais teorias relacionadas ao estudo do comportamento do consumidor, c) Inserir o entendimento do comportamento de manada dentro das teorias comportamentais de estudo do consumidor, d) Criar uma escala para medir o comportamento de manada.

Iniciou-se o estudo partindo de uma pesquisa bibliográfica para resgatar as referências teóricas publicadas. Construiu-se um questionário estruturado que foi aplicado a consumidores destes estabelecimentos. Com os dados obtidos utilizou-se o software SPSS para validação dos indicadores 
levantados no estudo, e consequentemente a validação da escala.

O artigo está estruturado da seguinte forma. Além desta introdução, apresenta-se o referencial teórico; procedimentos metodológicos; apresentação dos resultados e discussão; e termina com as considerações finais.

\section{Comportamento do consumidor}

Para entender as possíveis influências de outras pessoas no momento de decisão de compra, esta seção trata de aspectos relacionados ao comportamento do consumidor. A linha de raciocínio configura-se da seguinte forma: apresenta-se o comportamento do consumidor com as principais áreas que estudam este fenômeno; trata-se o modelo BPM (Behavior Perspective Model), uma configuração usual para compreender os processos de escolha dos indivíduos, e como busca certo Conforto Cognitivo; destacase o efeito FARM, que leva a Heurística na tomada de decisão, visto que, para uma melhor satisfação dos consumidores nos momentos de decisão buscam a Conformidade Social, que o levará ao Efeito Manada no momento de sua escolha.

\section{Comportamento do Consumidor, parâmetros conceituais}

Uma das ciências usadas para entender o comportamento de compra é a Microeconomia, campo das Ciências Econômicas que estuda o comportamento dos agentes, além do resultado de suas interações múltiplas, uma estrutura baseada nos princípios da otimização e do equilíbrio (Varian, 2003). O primeiro afirma que as pessoas buscam atingir o melhor padrão de consumo, otimizando as ofertas e as suas escolhas. O segundo indica que o ajuste de preços ocorre de maneira a igualar a demanda do consumidor à oferta das empresas.

Ressalta-se ainda que muitos comportamentos são desencadeados por fatores circunstanciais. Blackwell et al (2005) os divide em três grupos: 1) As diferenças individuais como demografia, psicografia, valores e personalidade; recursos do consumidor, como tempo, dinheiro e atenção; motivação que compreende o conhecimento e atitudes. 2) As influências ambientais, cultura, classe social, família, influência pessoal e situação. 3) E, os processos psicológicos que incluem processamento de informação, aprendizagem e mudança de comportamento e de atitude.

Voltando aos princípios econômicos, destaca-se que para fins de simplificação, os modelos partem do pressuposto que o consumidor é capaz de ordenar suas preferências, possui racionalidade ilimitada, e atua num ambiente de informação perfeita. É a representação do homem-econômico (Homo economicus). O pressuposto neoclássico de que o homem busca maximizar seu bem-estar foi formalizado matematicamente no que se chamou de Função de Utilidade - delineando suas preferências reveladas e da renda do indivíduo, é possível derivar a função e encontrar seu ponto de máximo (Ng; Tseng,2017).

Porém, esse modelo ignora fatores psicológicos e a origem do comportamento humano. Além disso, é sabido que o indivíduo não possui o controle e acesso irrestrito a toda informação, e essa assimetria afeta o comportamento. Ao expandir o número de variáveis na compreensão do Homo economicus, principalmente a ideia de que as regras sociais afetam o comportamento, não se perde a essência do indivíduo que age visando sua satisfação individual, mas ganha-se em riqueza de detalhes e aproxima da ideia do Homo sociologicus, um ente que não é totalmente movido pelo auto interesse, mas também é responsivo a forças externas que escapam ao seu controle (Ng; Tseng,2017).

Em termos mercadológicos, pode-se afirmar que, para que as empresas consigam satisfazer as necessidades e desejos dos clientes, é importante o entendimento do comportamento de compra dos consumidores, que conforme a literatura mercadológica, consiste em entender como indivíduos, grupos e organizações selecionam, compram, usam e descartam bens, serviços, ideias ou experiências para satisfazer suas necessidades e desejos (Kotler \& Keller, 2012; Oliveira, 2007). Gade (1998), destaca que 
o estudo do comportamento do consumidor são as atividades físicas, mentais e emocionais realizadas na seleção, compra e uso de produtos e serviços para a satisfação das necessidades e desejos.

Cabe destacar que os estudos em Marketing para o entendimento do comportamento do consumidor consideram que os mesmos, em seu processo de compra, são influenciados por fatores culturais (hábitos e costumes inerentes a uma determinado grupo), sociais (a pressão de determinados grupos sociais para padronização de comportamentos aceitáveis pelo grupo), Pessoais (comportamentos relativos a fase que os clientes se encontram em seu ciclo de vida) e psicológicos (relativos a motivação dos consumidores) como apresentado nos estudos de Cobra (1992), Engel (2005), Kotler e Keller (2012), Limeira (2009), Oliveira (2007), Rocha (2015), Samara e Morsch (2005), Sheth, Mittal e Newman (2001) e Solomon (2009).

\section{Comportamento do consumidor: enfoque cognitivista e comportamental}

Ressalta-se que a abordagem psicológica divide-se em duas vertentes: o enfoque cognitivista e comportamental. Se na formulação da econômica clássica o consumidor é visto como alguém capaz de lidar com uma infinidade de informações e fazer sempre a melhor escolha, a abordagem cognitiva também se baseia nessas premissas ao compreender a escolha do consumidor como um processo de cálculo e tomada de decisão comandado pelo intelecto e pela racionalidade, ocorrendo como resposta à um estímulo mental inicial. Segue o mesmo esquema do comportamento racional maximizador, sendo uma explicação mais refinada e aprofundada (Nalini et al., 2013).

A abordagem comportamental analisa as interações do consumidor com o ambiente de consumo. Essas interações dão origem e mantêm operantes os vários padrões através de princípios de aprendizagem. Aprende-se a: escolher produtos, a negociar descontos, prazos de pagamento, avaliar qualidade, reivindicar trocas e/ou reparos etc. Pode-se estabelecer e compreender padrões - sejam individuais ou coletivos ao investigar o processo psicológico da aprendizagem (Nalini et al., 2013).

Ainda aos aspetos relacionados a aprendizagem, teóricos em Marketing contemplam o tema nos fatores psicológicos. Para Cobra (1992), Kotler e Keller (2012), Limeira (2009), Oliveira (2007), Rocha (2015), Samara e Morsch (2005), os consumidores aprendem determinados comportamentos que são replicados em situações que apresentem as mesmas características. Isso permite que o consumidor generalize sua opinião a outras situações correlatas, em um processo contínuo de aprendizagem.

\section{BPM (Behavioral Perspective Model)}

Nalini, et al. (2013), destacam que entre as várias formas de estudar o comportamento do consumidor, existe o modelo Behavioral Perspective Model (BPM). Desenvolvido por Gordon Robert Foxall em 2010, e baseado nas teorias behavioristas de Burrhus Frederic Skinner, o BPM busca refutar a ideia de que as causas do consumo são fruto de processos mentais exclusivamente individuais, e que o histórico do consumidor, bem como fatores ambientais, são importantes em seu processo decisório.

Cabe destaque que vários modelos comportamentais são usados no processo de entendimento do comportamento do consumidor, como o modelo de Engel-Blackwell-Miniard (2005), que compreende as fases: Reconhecimento do Problema, Busca de Informações, Avaliação das Alternativas, Decisão de Compra e Comportamento Pós-compra, modelo esse consagrado na literatura mercadológica, como pode-se notar nos trabalhos seminais de Cobra (1992), Churchill e Peter (2000), Engel (2005), Karslakian (2012), Kotler e Keller (2012), Limeira (2009), Mowen (2003), Rocha (2015), Oliveira (2007), Samara e Morsch (2005), Sheth et al (2001) e Solomon (2009). Destaca-se que essas fases, possuem como alicerce os fatores que influenciam nesse processo, como os Fatores Culturais, Sociais, Pessoais e Psicológicos, que corroboram com o modelo BPM.

Analisar o ambiente de consumo tem se mostrado uma ferramenta eficaz. No BPM, além do histórico de aprendizagem, considera-se a abertura do cenário de consumo - aberto e fechado, tendo como base 

similares

o grau de interação do cliente com os produtos, bem como eventos a posteriori que influenciam no momento da escolha, como os sentimentos que o cliente possui após a aquisição de um produto, como status ou frustração (Nalini et al., 2013).

\section{Conforto Cognitivo}

Tendo em vista como determinados indivíduos decidem, Kahneman (1979), tira o foco da questão entre o racional e o irracional. O seu estudo tem como premissa básica a ideia de que temos uma incapacidade inata e resiliente de reconhecer nossa má capacidade de avaliação. Descreve o sistema cognitivo dividido em Sistema 1 (S1) e Sistema 2 (S2). O primeiro é suscetível a influenciar o último, sem S2 estar ciente dessa influência. S1 o mais intuitivo opera automaticamente e de forma rápida. Com pouco ou nenhum esforço, e sem sentido de controle voluntário enquanto S2 é mais deliberado e é governado por lógica e raciocínio. Todas informações recebidas são primeiro avaliadas por S1, que determina se é necessário um esforço do S2. Os Métodos de S1 são de natureza associativa - dedutiva, pois, as pessoas julgam sobre fatos, ou com relação a valores (Kahneman, 1979) -chamado de indução.

Abordando a indução enquanto processo cognitivo em meio ao comportamento coletivo, é possível traçar um panorama dessa observação considerando aspectos que envolvem o conforto individual. Dolan e Kahneman (2008) sugerem que o conforto cognitivo é uma das características de (S1) que traz a sensação tranquilizadora e de familiaridade. Deste modo um dos grandes atributos que determinam o comportamento de manada então é o conforto cognitivo. Os inputs, ou estímulos que garantem a facilidade cognitivo deste sistema podem ser gerados principalmente por entradas como: (a) experiência repetida, (b) bom humor/ boas sensações.

A Repetição (a) predispõe ao conforto cognitivo e uma sensação tranquilizadora, conceito trazido Zajonc (1968). O "efeito de mera exposição," (a) experiência repetida, onde, quanto mais um indivíduo é exposto a alguma coisa, maior a probabilidade de gostar dela. Isso se aplica igualmente a objetos e pessoas (Miller \& Brehm, 2006). Monahan, Murphy e Zajonc (2001) reforçam a tendência natural de convergência comportamental em ambientes sociais que tenham presença de situações repetidas.

No que se refere ao (b) bom humor/boas sensações, um estado de bom humor afrouxa o controle do S2, "[...] quando de bom humor, as pessoas se tornam mais intuitivas e mais criativas, mas também menos vigilantes e mais propensas a cometer erros lógicos. Aqui, mais uma vez, como no efeito de mera exposição, a conexão faz sentido biológico" (Kahneman, 2001, p. 69). Bom humor é sinal de que as coisas estão indo bem, o ambiente está seguro e não há problema em manter a guarda baixa. Portanto, o conforto cognitivo é tanto uma causa como uma consequência de uma sensação agradável, conforme destacam Garcia-Marques (2003) e Cacioppo (2001).

\section{Efeito FARM (Familiarity as Regulation Mechanism)}

Considerando que o ambiente favorece as escolhas por meio da exposição de determinados estímulos para trazer consigo certa confiança e segurança, pode-se observar que a questão da familiaridade passa a ser um fator importante e circunstancial.

A hipótese de ativação/desativação designada de FARM (Jacoby \& Kelley, 1990; Schwarz \& Clore, 1996; Smith, 1994) explica que é a forma de regular a ativação de um ou outro modo de processamento, sendo um sentimento que em princípio traduz a aplicabilidade/ adequação da informação recebida e representada na memória. O fato de um estímulo se adequar a uma representação mnésica torna o seu processamento mais fluente, familiar e, consequentemente, permite uma decisão segura. O reencontro com um estímulo resulta num processamento mais fácil, fluente a experiência subjetivamente como um sentimento de familiaridade.

O papel da motivação em termos objetivos (matching), é um processo de detecção de uma 
correspondência biunívoca entre a informação recebida dos órgãos dos sentidos e a informação armazenada na memória. Esta correspondência pressupõe ser experiência como um sentimento. Visto ser a atenção seletiva (Broadbent, 1958; Bruner, 1957), não se espera que todos os aspectos de um estímulo recebam igual atenção numa dada altura (Smith \& Zarate, 1992; Higgins, 1996), e as características do contexto ajudam a definir o estímulo em causa. Como consequência, a semelhança entre um estímulo e uma representação mnésica seja, ela própria, variável - a semelhança depende da forma como os processos percebem e interpretam os estímulos (Smith \& Zarate, 1992). Variáveis de capacidade (p. ex.: distração) reduzem os detalhes percebidos num estímulo e aumentam a probabilidade de correspondência com algum traço na memória. Assim sendo a hipótese da familiaridade enquanto mecanismo de regulação, implica que a redução de recursos cognitivos aumente a probabilidade de um processamento não-analítico (Smith \& Zarate, 1992).

\section{Heurística - tomada de decisão}

Heurística é um procedimento que ajuda a encontrar respostas adequadas, ainda que geralmente imperfeitas, para perguntas difíceis. É pautada por (a) crowdness (b) reduzir incertezas (c) economia de energia (Luppe \& De Angelo, 2010). Quando as decisões são tomadas de maneira irracional, é comum que haja estratégias que ignoram algumas informações para tornar a escolha fácil, rápida e prática. $\mathrm{O}$ nome que se dá a este fenômeno proposto por Gigerenzer (2000) é Heurísticas Rápidas e Frugais, que empregam tempo, conhecimento e computação mínimos para fazer escolhas.

A ideia de que os indivíduos não maximizam a satisfação de modo amplo, mas parcial, considerando somente as informações disponíveis, foi formulada por Herbert Simon, "racionalidade limitada". Simon (1957) argumenta que os tomadores de decisão têm limitações no processamento de informações. Não decidem de modo inteiramente racional. Tentam fazer o melhor, dadas as limitações a que estão sujeitos. Com tais limitações, as pessoas se valem de "regras práticas" ou heurísticas para tomar decisões.

As pessoas não levam em conta todas as informações e focam no que as preocupam. Ao invés de enfrentarem informações potencialmente contraditórias, e selecionar o que pode ser relevante, reduzem a sobrecarga de informação. $O$ ambiente permeado pela incerteza e as lacunas de informação são apontados como aspectos que afastam os indivíduos do comportamento racional (Sherman \& Corty, 1984). Julgamentos realizados em situações de incerteza são frequentemente embasados em um número limitado de heurísticas simplificadoras. Uma alternativa cognitiva que explica o erro humano sem assumir a irracionalidade (Gilovich; Griffin; Kahneman, 2002).

As possibilidades de interação podem ocorrer no ambiente de consumo, e até mesmo nas simples interações do dia a dia, através de conversas ou observações, (Libai, et al., 2010). Podem também, de modo contrário, oferecer prejuízos, pois existem consumidores que se comportam de maneira disfuncional (Wilkes, 1978; Fullerton \& Punj, 1993; Daunt \& Greer, 2015). Comportamento Disfuncional do Cliente (CDC) é entendido como: “[...] ações dos clientes que, intencionalmente ou não, aberta ou veladamente, agem de uma maneira que, de alguma forma, rompem encontros de serviço que de outra forma seriam funcionais" (Harris \& Reynolds, 2003, p. 144-161). A interação entre clientes que agem de maneira disfuncional pode causar, entre outras consequências, o efeito dominó, a disseminação do comportamento disfuncional do cliente a partir de um cliente disfuncional para outros clientes próximos (Libai, et al., 2010).

Também pode-se inferir que que quando consumidores percebem um restaurante lotado, eles relacionam o alto nível de crowdedness a alta qualidade de alimentos e boa reputação. Pelo contrário, no caso de um restaurante com poucos clientes, a quietude é remetida a pouca reputação (Tse; Leo Sin; Yim, 2002).

O comportamento médio dos agentes que participam de um mercado pode indicar a tendência futura 
das variáveis relevantes para a tomada de decisão. Nesse caso, a adesão ao comportamento médio pode ser vista como uma forma de se tomar decisões com base em expectativas que não estarão muito distantes dos resultados. Dessa forma, pode-se entender o "comportamento de manada" como uma estratégia de minimização de erros de previsão (Tse; Leo Sin; Yim, 2002) .

O homem, investidor e racional, busca maximizar a sua utilidade esperada. Apesar desse pressuposto ser considerado de menor relevância, estudos iniciados no final da década de 1970 por Daniel Kahneman e Amos Tversky (1979), põe em dúvida esse pressuposto adotado nas teorias financeiras e de decisão. Os autores sabiam que a teoria de Utilidade Esperada dominava a análise de decisão sob condições de risco, e aceita como um modelo normativo de escolha racional aplicado como modelo descritivo do comportamento econômico. No entanto, seu trabalho mostrou evidências de que, em uma série de escolhas proporcionadas a sujeitos de uma pesquisa, a teoria da utilidade esperada era constantemente violada dependendo da abordagem (framing) dada ao problema em questão (Tversky \& Kahneman, 1981).

Segundo a Prospect Theory de Kahneman e Tversky, o indivíduo é avesso ao risco para ganhos, mas é propenso ao risco para perdas. Uma pessoa avessa ao risco é aquela que prefere a certeza de um ganho, a qualquer prospecto de risco cujo ganho esperado seja X. Para o prospecto das perdas, a pessoa. De acordo com Kimura, Basso e Krauter (2006), o comportamento humano é influenciado por vários aspectos psicológicos que podem distorcer a identificação e percepção dos fatos, o que conduz a uma decisão tendo como base julgamentos individuais, nos quais a racionalidade imposta pela teoria da utilidade esperada por não ser obedecida.

Esse conceito de utilidade esperada é o mesmo que induz a esperança, dado o valor daquela circunstância ou oportunidade, e está onipresente na maior parte dos modelos econômicos que procuram modelar o comportamento do consumidor em situações de incerteza.

\section{Conformidade Social}

Para entender como indivíduos replicam comportamentos para simplificar as suas decisões, destaca-se a teoria da Conformidade Social. Araújo (2009), explica que Solomon Asch foi o pioneiro em psicologia social e criador de trabalhos voltados para a formação de impressões, sugestão de prestígio, conformidade, entre outros. E o mais famoso estudo, o efeito da pressão social na conformidade, com tema central o seu experimento em encontrar indícios do poder de influência que os grupos exercem sobre os indivíduos. Sua investigação queria provar que o simples desejo de pertencer a um grupo faz com que as pessoas abrissem mão de suas opiniões, conviç̧ões e individualidades. Segundo seu modelo teórico, o item social é pautado por Desindividualização, Reputação, e Aprendizado.

\section{Desindividualização}

É o ato de se desvincular da própria ética em prol do grupo. Os primeiros teóricos da Desindividualização foram Festinger, Pepitone e Newcombe (1952) e Zimbardo (1969). Defendiam que quando em grupos com os quais se identificam, as pessoas passam por um processo de perda das restrições morais e comportamentais. Tornam-se mais suscetíveis a agir de forma diferente e até mesmo de se engajar em práticas antissociais, de acordo com as orientações do grupo maior. Pessoas em grupos tendem a perder parte de seu próprio autoconhecimento e autocontenção. Tornam-se menos indivíduos e mais anônimas. Em certo sentido, farão coisas em grupos que não fariam sozinhas porque se sentem menos responsáveis por suas ações (Jesus, 2013).

\section{Reputação}

A questão que sugere o efeito manada, pode ser comumente associado ao sentimento de boa reputação. Falhar em grupo remete a uma segurança maior e um prestigio relevado se levarmos em consideração 
que você não foi o único a falhar na escolha. Logo, se outros falharam, é natural errar. Pensar por este ângulo fornece uma sensação de conformidade. O problema é quando se erra sozinho, pois essa falha compete a questões que perpassam a insegurança e incerteza da sua capacidade e competência de selecionar aquilo que é certo.

\section{Aprendizado}

Neste ponto destaca-se os Neurônio Espelho. O neurofisiologista italiano Rizzolatti $(1996,1998)$ e colaboradores pesquisavam a área pré-motora de macacos Rhesus na década de 1990. Demonstraram que alguns neurônios da área F5, localizada no lobo frontal, eram ativados quando o animal realizava um movimento com uma finalidade específica, também eram ativados quando o animal observava um outro indivíduo realizando a mesma tarefa. Os resultados sugerem que existe um sistema de neurônios espelho (SNE) em humanos distribuído em várias áreas corticais frontoparietais. Recentemente, Buccino et al. (2004), através de um estudo com ressonância magnética funcional (fMRI), demonstraram a ativação de áreas frontais (giro frontal inferior e córtex pré-mortor) em humanos durante a execução-observação de ações realizadas com a mão, com a boca e com os pés.

Este espelhamento não depende obrigatoriamente da nossa memória. Se alguém faz um movimento corporal complexo que nunca realizamos antes, os nossos neurônios-espelho identificam no nosso sistema corporal os mecanismos proprioceptivos e musculares correspondentes e tendemos a imitar, inconscientemente, aquilo que observamos, ouvimos ou percebemos de alguma forma. As emoções também podem ser espelhadas pois, quando vemos alguém chorar, por exemplo, nossas células refletem a expressão do sentimento que pode estar por trás das lágrimas e trazem de volta a lembrança de momento. A essa capacidade dá-se o nome de empatia, uma das chaves para decifrar o comportamento e a socialização do ser humano (Dobbs, 2006).

De acordo com Rizzolatti e Craighero (2004), o que caracteriza e garante a sobrevivência dos seres humanos é a nossa capacidade de nos organizar socialmente, e isso só é possível porque somos seres capazes de entender a ação de outras pessoas. Além disso, também somos capazes de aprender através da imitação e essa faculdade é a base da cultura humana.

\section{Comportamento de manada}

Existem diversas situações sociais sobre as quais somos influenciados nas decisões levando em consideração as escolhas do outro por uma questão de sentir-se seguro, pois prestar atenção em outras pessoas pode ser uma maneira de extrair informações importantes que elas possuem e nós não. Frequentemente, em nosso cotidiano indivíduos decidem sobre qual shopping, loja ou restaurantes frequentar com base em quão populares parecem ser (Sanches, 2013), em nosso caso em particular, existem indícios que consumidores podem fazer as suas escolhas em um restaurante pelo simples fato de replicar comportamentos para assegurar melhores decisões.

Apesar da palavra "manada" possuir uma conotação negativa por estar contida no mesmo campo semântico de termos como volatilidade, crise e instabilidade (por estar associado ao não domínio intelectual), é importante ressaltar que, segundo Mosca (2009) é por meio dessa proteção psicológica que o mercado encontra a intensificação de vendas. Estas correntes se opõem de forma tradicional à "teoria neoclássica", que se baseia na "racionalidade" dos agentes econômicos e consequentemente em uma provável capacidade de agir de forma cartesiana nas escolhas.

\section{Procedimentos metodológicos}

Como há poucos estudos sobre os fenômenos que envolvem a tendência de um grupo de indivíduos em influenciar outros em ambientes de bares e restaurantes, houve a necessidade de um estudo exploratório que resultou na revisão bibliográfica. Segundo Gil (1999), a pesquisa exploratória tem como objetivo principal desenvolver, esclarecer e modificar conceitos e ideias, tendo em vista a 
formulação de problemas mais precisos e hipóteses pesquisáveis para estudos posteriores. A pesquisa teve uma fase descritiva, que de acordo com Malhotra (2006) é marcada por um enunciado claro do problema, por hipóteses específicas e pela necessidade detalhada de informações, porém destaca-se que neste trabalho não cabia a adoção de hipótese por se tratar do desenvolvimento de uma escala.

A revisão da teoria possibilitou o agrupamento e a sistematização da teoria em três dimensões, tabela 1. A partir daí foi desenvolvido um questionário estruturado, baseado na escala de Likert de 7 pontos. As afirmações foram feitas em primeira pessoa e logo abaixo delas existia uma escala de sete pontos no qual em um dos extremos continha a afirmação "concordo totalmente" e no outro extremo "discordo totalmente".

Tabela 1 - Grupos de conhecimento e critérios de determinação

\begin{tabular}{|l|l|}
\hline GRUPO & CRITÉRIO \\
\hline Conforto Cognitivo & $\begin{array}{l}\text { Experiências repetidas } \\
\text { Bom humor }\end{array}$ \\
\hline \multirow{3}{*}{ Heurística } & $\begin{array}{l}\text { Economia de energia } \\
\text { Crowndness }\end{array}$ \\
\hline \multirow{3}{*}{ Conformidade Social } & Redução de incerteza \\
\hline & Aprendizado \\
& Reputação \\
\hline
\end{tabular}

Fonte: Pesquisa (2017)

A construção considerou três questões para cada um dos seguintes atributos: experiência repetidas, bom humor, economia de energia, crowdness, redução de incerteza, aprendizado, reputação e desindividualização. Um total de 24 perguntas referentes à teoria e mais três perguntas socioeconômicas. Após a construção do modelo inicial da escala, o instrumento passou então para o processo de Validação de Face. Quatro especialistas foram consultados, sendo dois marketólogos e dois psicólogos sociais, que sugeriram mudanças pontuais. Foi utilizada a técnica de cadeia de informantes ou snowball (Biernacki \& Waldorf, 1981). Após as mudanças o questionário foi submetido a um préteste com cinco pessoas. Os respondentes foram convidados individualmente com o intuito de garantir que pudessem se expressar sobre a clareza, tamanho e compreensão do questionário. O estudo foi realizado com amostra por conveniência constituída por 257 pessoas. Os dados foram colhidos por questionário online através do Google Survey e o link da pesquisa enviado por e-mail e facebook no período de 18 de novembro a 28 de novembro de 2017.

Os dados foram avaliados com análise fatorial de componentes principais, método estatístico multivariado cujo objetivo é agrupar variáveis aleatórias em grupos formados por variáveis fortemente relacionadas, chamados fatores ou variáveis latentes (Carvalho, 2013). Este método foi escolhido devido a busca de redução de dados para que elas possam descrever o que são chamadas de combinações lineares das variáveis originais, designadas componentes principais (Maroco, 2003; Pestatana \& Gageiro, 2005).

Para validar a análise, o primeiro passo foi o cálculo da matriz de correlação para verificar a associação entre as variáveis, com o objetivo de que com alguns componentes se possa representar grande parte da variabilidade de dados. A medida de adequação da amostragem foi analisada com o método KMO, ou KaiserMeyer-Olkin. Este método indica se a correlação entre os pares de variáveis retirados da primeira etapa pode ser explicada por outras variáveis. A esferecidade de Bertlett é usada após o KMO para testar a hipótese da matriz das correlações serem a matriz identidade, seguido do uso da matriz de Antiimagem para nova triagem. Apesar de existir diversos métodos para extração de componentes, no caso deste trabalho isso foi feito pelo método das componentes principais, neste caso por KMO pelo número de variáveis ser menor que 30. 


\section{Apresentação e análise dos resultados}

Os primeiros dados tabelados foram os socioeconômicos, para identificar o público que participou da pesquisa. Como pode ser visto no gráfico 1, o maior número de respondentes possui faixa de renda de média entre $\mathrm{R} \$ 1875,00$ a $\mathrm{R} \$ 3748,00$, seguida da faixa de renda logo acima, entre $\mathrm{R} \$ 3749,00$ a $\mathrm{R} \$ 9370,00$. A faixa de renda menos atingida foi a de maior poder aquisitivo, com renda superior a $\mathrm{R} \$ 18741,00$.

Gráfico 1 - Demonstrativo de distribuição de renda

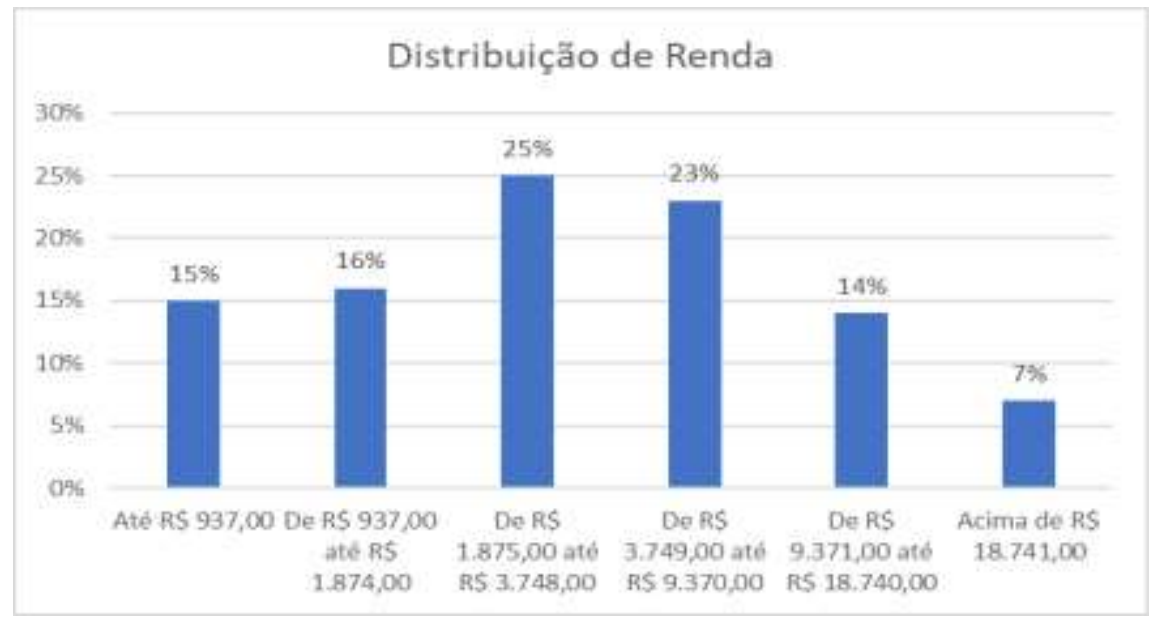

Fonte: Pesquisa (2017)

A idade dos entrevistados é demonstrada no gráfico 2. As faixas entre 18 e 23 anos, 24 a 30 anos e 30 a 35 anos ocupam proporções próximas de quantidades de resposta, posicionando a maioria dos respondentes. Ao mesmo tempo, a faixa etária de 14 a 17 anos tem expressividade baixa.

\section{Gráfico 2-Demonstrativo de distribuição etária entre respondentes}

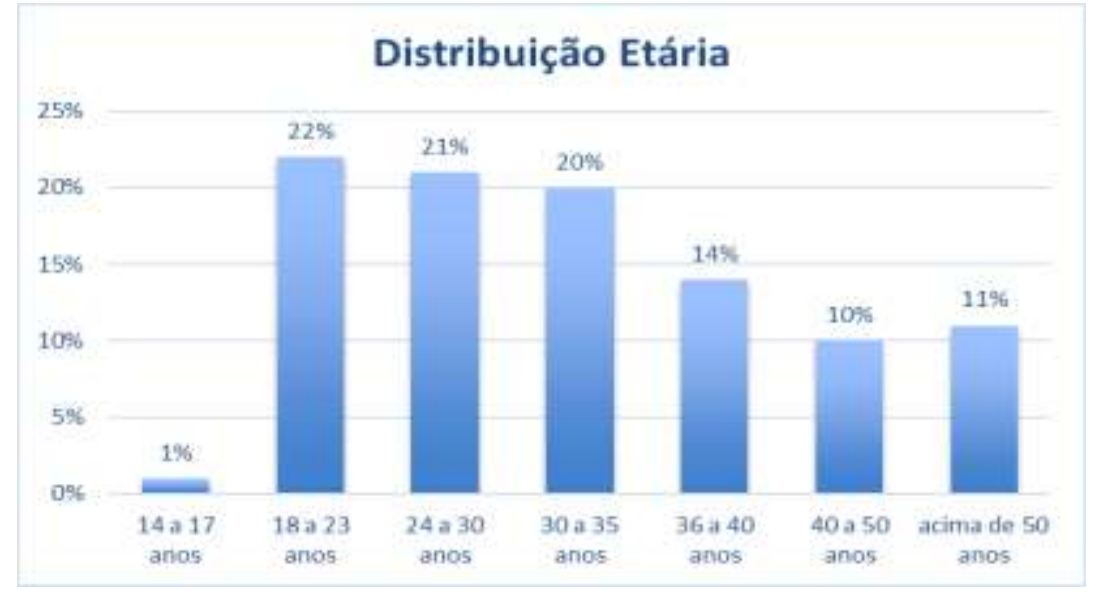

Fonte: Pesquisa (2017)

Posteriormente foram analisados os dados referentes a atitude dos respondentes sobre decisões tomadas na hora da escolha de um estabelecimento de A\&B. A análise fatorial exploratória foi utilizada para estabelecer os elementos base e as etapas realizadas para se chegar ao resultado final. O primeiro passo empregado foi a rotação do tipo varimax, que explica a relação entre um conjunto de variáveis com extração por meio do método dos componentes principais. Os primeiros resultados eliminados pelas comunalidades foram, em primeira rodada a variável 1 , com 0,276 , em segunda rodada a variável 9 com 0,330 e em terceira rodada a variável 18, com 0,485. Os resultados das demais comunalidades são apresentados na tabela 2, com extração de valores variáveis entre 0,511 da variável 22 até 0,762 da variável 4. 


\section{Tabela 2 - Comunalidades entre variáveis com rotação Equamax}

\begin{tabular}{|c|c|c|}
\hline \multicolumn{3}{|l|}{ Comunalidades } \\
\hline & Inicial & Extração \\
\hline $\begin{array}{l}\text { 2) Estou viajando a trabalho no interior e vou a um restaurante desconhecido e possuo pouco tempo } \\
\text { para almoçar. Neste caso eu observaria qual prato a maioria das pessoas ao redor escolhem antes de fazer } \\
\text { meu pedido. }\end{array}$ & 1.000 & .639 \\
\hline $\begin{array}{l}\text { 3) Vou a uma pizzaria com muitas pessoas com gostos diferentes. Nesta situação, tendo a olhar os } \\
\text { sabores mais consumidos naquele local para fazer o meu pedido. }\end{array}$ & 1.000 & .513 \\
\hline $\begin{array}{l}\text { 4) Eu estou passando um fim de semana no litoral e então decido entrar em um charmoso restaurante } \\
\text { peruano. Ao me acomodar, noto que, apesar de estar em horário de almoço o estabelecimento tem } \\
\text { apenas um cliente, neste caso eu me retiro do restaurante. }\end{array}$ & 1.000 & .762 \\
\hline $\begin{array}{l}\text { 5) Estou com fome e ao me deparar com duas lanchonetes desconhecidas em uma praça de alimentação, } \\
\text { prefiro a que possui mais gente pois o fato de ter maior clientela indica melhor comida. }\end{array}$ & 1.000 & .594 \\
\hline $\begin{array}{l}\text { 6) Eu e meu namorado(a) fomos a uma doceria que está muito cheia, apesar de eu gostar mais de } \\
\text { quindim, o comportamento médio das pessoas demonstra que o doce mais vendido é o churros. Dessa } \\
\text { forma, tendo a escolher o churros. }\end{array}$ & 1.000 & .610 \\
\hline $\begin{array}{l}\text { 7) Estou no show de minha banda favorita. No intervalo resolvo tomar um Chopp. Ao me deparar com } \\
\text { uma marca nova no mercado, na qual possui muitas pessoas consumindo esse produto, eu tendo a } \\
\text { experimentar a nova marca. }\end{array}$ & 1.000 & .565 \\
\hline $\begin{array}{l}\text { 8) Estou em uma praia na Tailândia, a qual visito pela primeira vez, e percebi que ali é muito comum } \\
\text { consumir um prato específico na hora do almoço. Eu tendo a pedir o prato. }\end{array}$ & 1.000 & .622 \\
\hline $\begin{array}{l}\text { 10) Estou em um restaurante temático de comida eslava. Não conheço os pratos e assim pergunto ao } \\
\text { garçom sobre o prato mais vendido antes de fazer a melhor opção. }\end{array}$ & 1.000 & .578 \\
\hline $\begin{array}{l}\text { 11) Estou em um jantar onde todos estão comendo Escargot. Quero experimentar aquela iguaria, mas } \\
\text { não sei como usar o utensílio para comê-la. Eu tendo a olhar para os comensais ao lado para aprender a } \\
\text { comer como eles comem. }\end{array}$ & 1.000 & .636 \\
\hline $\begin{array}{l}\text { 12) Ao visitar um bar especializado em saquê percebo que a maioria das pessoas ao brindar levantam } \\
\text { vigorosamente copos em formato de caixinhas e falam Kanpai!!! Eu tendo a repetir o mesmo gesto. }\end{array}$ & 1.000 & .724 \\
\hline $\begin{array}{l}\text { 13) Eu estou em um restaurante no qual os garçons oferecem um pequeno bolo e batem palma de } \\
\text { felicitações aos aniversariantes. A ação se repete muitas vezes e o clima é de bastante alegria, todos batem } \\
\text { palma. Eu tendo a bater palmas também. }\end{array}$ & 1.000 & .665 \\
\hline $\begin{array}{l}\text { 14) Sempre que vou a um restaurante que não conheço, e vejo muitas pessoas elogiando um mesmo } \\
\text { prato que já experimentei em outro lugar, mas não gostei, me disponho a experimentar novamente. }\end{array}$ & 1.000 & .509 \\
\hline $\begin{array}{l}\text { 15) Estou fechando um negócio em um restaurante com um grupo de pessoas. Como não conheço os } \\
\text { pratos, eu tendo a escolher os mesmos itens da maioria dos integrantes para não errar sozinho na minha } \\
\text { escolha. }\end{array}$ & 1.000 & .608 \\
\hline $\begin{array}{l}\text { 16) Vou a restaurante de um renomado Chef pela primeira vez. Caso ele me indique um prato específico } \\
\text { que é muito vendido e que eu nunca experimentei, sigo a sugestão dele. }\end{array}$ & 1.000 & .584 \\
\hline $\begin{array}{l}\text { 17) Mesmo não tendo uma dieta rica em açúcar, ao viajar para a Disney eu tendo a experimentar alguns } \\
\text { doces que são vendidos nos parques pois me sinto desinibido para comer esse produto sem peso na } \\
\text { consciência. }\end{array}$ & 1.000 & .660 \\
\hline $\begin{array}{l}\text { 19) Eu gosto de comer hambúrguer com as mãos, mas ao visitar uma hamburgueria muito sofisticada } \\
\text { tendo a seguir as demais pessoas do local e comer tal produto de talher. }\end{array}$ & 1.000 & .687 \\
\hline $\begin{array}{l}\text { 20) Eu estou em um restaurante desconhecido e vejo muitas pessoas consumindo o mesmo prato. Eu, } \\
\text { então, me sinto confortável para experimentar aquele prato que nunca comi. }\end{array}$ & 1.000 & .726 \\
\hline $\begin{array}{l}\text { 21) Eu estou em restaurante que conheço e vejo muitas pessoas consumindo um mesmo prato que já vi, } \\
\text { mas nunca experimentei. Isso me deixa confortável em experimentar esse produto. }\end{array}$ & 1.000 & .743 \\
\hline $\begin{array}{l}\text { 22) Estou de férias na praia com um grupo de amigos em um ambiente relaxante. Vamos a uma } \\
\text { sorveteria, tendo a experimentar um sabor que nunca experimentei pois todos estão pedindo. }\end{array}$ & 1.000 & .511 \\
\hline $\begin{array}{l}\text { 23) Eu estou em um restaurante desconhecido e em geral peço o mesmo prato que as outras pessoas } \\
\text { estão pedindo porque isso reduz a minha insegurança. }\end{array}$ & 1.000 & .636 \\
\hline
\end{tabular}

Extraction Method: Principal Component Analysis.

Fonte: Pesquisa (2017)

Em seguida foi utilizada a matriz denominada anti-imagem, ou MSA - Measure of Sampling Adequacy, uma forma de obter indícios sobre as necessidades de eliminação de determinada variável no modelo. A 
Tabela 3 apresenta que as variações nessa matriz foram de valores entre 0,555 na variável 4 até 0,907 na variável 22.

Tabela 3 - Measure of Sampling Adequacy - MSA

\section{Anti-image Matrices}

2) Estou viajando a trabalho no interior e vou a um restaurante desconhecido e possuo pouco tempo para almoçar. Neste caso eu observaria qual prato a maioria das pessoas ao redor escolhem antes de fazer meu pedido.

3) Vou a uma pizzaria com muitas pessoas com gostos diferentes. Nesta situação, tendo a olhar os sabores mais consumidos naquele local para fazer o meu pedido.

4) Eu estou passando um fim de semana no litoral e então decido entrar em um charmoso restaurante peruano. Ao me acomodar, noto que, apesar de estar em horário de almoço o estabelecimento tem apenas um cliente, neste caso eu me retiro do restaurante.

5) Estou com fome e ao me deparar com duas lanchonetes desconhecidas em uma praça de alimentação, prefiro a que possui mais gente pois o fato de ter maior clientela indica melhor comida.

6) Eu e meu namorado(a) fomos a uma doceria que está muito cheia, apesar de eu gostar mais de quindim, o comportamento médio das pessoas demonstra que o doce mais vendido é o churros. Dessa forma, tendo a escolher o churros.

7) Estou no show de minha banda favorita. No intervalo resolvo tomar um Chopp. Ao me deparar com uma marca nova no mercado, na qual possui muitas pessoas consumindo esse produto, eu tendo a experimentar a nova marca.

8) Estou em uma praia na Tailândia, a qual visito pela primeira vez, e percebi que ali é muito comum consumir um prato específico na hora do almoço. Eu tendo a pedir o prato.

10) Estou em um restaurante temático de comida eslava. Não conheço os pratos e assim pergunto ao garçom sobre o prato mais vendido antes de fazer a melhor opção.

11) Estou em um jantar onde todos estão comendo Escargot. Quero experimentar aquela iguaria, mas não sei como usar o utensílio para comê-la. Eu tendo a olhar para os comensais ao lado para aprender a comer como eles comem. 12) Ao visitar um bar especializado em saquê percebo que a maioria das pessoas ao brindar levantam vigorosamente copos em formato de caixinhas e falam Kanpai!!! Eu tendo a repetir o mesmo gesto.

13) Eu estou em um restaurante no qual os garçons oferecem um pequeno bolo e batem palma de felicitações aos aniversariantes. A ação se repete muitas vezes e o clima é de bastante alegria, todos batem palma. Eu tendo a bater palmas também.

14) Sempre que vou a um restaurante que não conheço, e vejo muitas pessoas elogiando um mesmo prato que já experimentei em outro lugar, mas não gostei, me disponho a experimentar novamente.

15) Estou fechando um negócio em um restaurante com um grupo de pessoas. Como não conheço os pratos, eu tendo a escolher os mesmos itens da maioria dos integrantes para não errar sozinho na minha escolha.

16) Vou a restaurante de um renomado Chef pela primeira vez. Caso ele me indique um prato específico que é muito vendido e que eu nunca experimentei, sigo a sugestão dele.

17) Mesmo não tendo uma dieta rica em açúcar, ao viajar para a Disney eu tendo a experimentar alguns doces que são vendidos nos parques pois me sinto desinibido para comer esse produto sem peso na consciência.

19) Eu gosto de comer hambúrguer com as mãos, mas ao visitar uma hamburgueria muito sofisticada tendo a seguir as demais pessoas do local e comer tal produto de talher.

20) Eu estou em um restaurante desconhecido e vejo muitas pessoas consumindo o mesmo prato. Eu, então, me sinto confortável para experimentar aquele prato que nunca comi.

21) Eu estou em restaurante que conheço e vejo muitas pessoas consumindo um mesmo prato que já vi, mas nunca experimentei. Isso me deixa confortável em experimentar esse produto.

22) Estou de férias na praia com um grupo de amigos em um ambiente relaxante. Vamos a uma sorveteria, tendo a experimentar um sabor que nunca experimentei pois todos estão pedindo.

23) Eu estou em um restaurante desconhecido e em geral peço o mesmo prato que as outras pessoas estão pedindo porque isso reduz a minha insegurança.

Fonte: Pesquisa (2017)

Para verificar a possibilidade de dados por analise fatorial a medida de adequação de amostra KMO, ou Kaiser-Meyer-Olkin, e o teste de Bartllet foram aplicados como apresentado na tabela 4. O nível de pontuação 0,810 indica que a amostra possui bons coeficientes e poderá ser utilizada na análise fatorial. Já sobre a esfericidade Bartllet, que testa a possibilidade de a matriz ser identidade, o nível de 
A construção e a validação de uma escala para mensurar o efeito manada dentro de restaurantes e similares

significância no caso estudado é menor que 0,001, portanto, as variáveis possuem correlação perfeita com elas mesmas e podem apresentar correlações com outras variáveis (Malhorta, 2006; Pestana \& Gageiro, 2005).

\section{Tabela 4 - KMO e Teste de Bartllet}

\begin{tabular}{|l|l|l|}
\hline \multicolumn{2}{|c|}{ KMO and Bartlett's Test } & .810 \\
\hline Kaiser-Meyer-Olkin Measure of Sampling Adequacy. & & 1.172 .449 \\
\hline Bartlett's Test of Sphericity & Approx. Chi-Square & 190 \\
\hline & df & .000 \\
\hline
\end{tabular}

Fonte: Pesquisa (2017)

A variância explicada foi o próximo passo dado, e demonstrada na tabela 4. São apresentados não só a variância de cada fator, mas também a explicação total da solução que demonstra que o modelo de 7 fatores explica $62 \%$ da variância, os demais 38\% são explicados por outros fatores.

Tabela 5 - Total da variância explicada pelo método das componentes principais

\begin{tabular}{|c|c|c|c|c|c|c|c|c|c|}
\hline \multicolumn{10}{|c|}{ Total Variance Explained } \\
\hline \multirow[t]{2}{*}{ Component } & \multicolumn{2}{|c|}{$\begin{array}{l}\text { Initial } \\
\text { Eigenvalues }\end{array}$} & \multirow[b]{2}{*}{$\begin{array}{l}\text { Cumula } \\
\text { tive } \%\end{array}$} & \multicolumn{3}{|c|}{$\begin{array}{l}\text { Extraction Sums of Squared } \\
\text { Loadings }\end{array}$} & \multicolumn{2}{|c|}{$\begin{array}{l}\text { Rotation Sums of } \\
\text { Squared Loadings }\end{array}$} & \multirow{2}{*}{$\begin{array}{l}\text { Cumulative } \\
\%\end{array}$} \\
\hline & Total & $\begin{array}{l}\% \text { of } \\
\text { Varianc } \\
\mathrm{e}\end{array}$ & & Total & $\begin{array}{l}\% \text { of } \\
\text { Variance }\end{array}$ & $\begin{array}{l}\text { Cumula } \\
\text { tive } \%\end{array}$ & Total & $\begin{array}{l}\% \text { of } \\
\text { Variance }\end{array}$ & \\
\hline 1 & 4.603 & 23.017 & 23.017 & 4.603 & 23.017 & 23.017 & 2.375 & 11.876 & 11.876 \\
\hline 2 & 2.080 & 10.401 & 33.418 & 2.080 & 10.401 & 33.418 & 2.306 & 11.528 & 23.404 \\
\hline 3 & 1.314 & 6.570 & 39.988 & 1.314 & 6.570 & 39.988 & 2.136 & 10.678 & 34.083 \\
\hline 4 & 1.255 & 6.275 & 46.263 & 1.255 & 6.275 & 46.263 & 1.516 & 7.582 & 41.665 \\
\hline 5 & 1.211 & 6.055 & 52.318 & 1.211 & 6.055 & 52.318 & 1.451 & 7.253 & 48.918 \\
\hline 6 & 1.083 & 5.417 & 57.735 & 1.083 & 5.417 & 57.735 & 1.411 & 7.055 & 55.973 \\
\hline 7 & 1.026 & 5.130 & 62.865 & 1.026 & 5.130 & 62.865 & 1.378 & 6.892 & 62.865 \\
\hline
\end{tabular}

Fonte: Pesquisa (2017). Extraction Method: Principal Component Analysis.

A tabela 5 mostra que $62,865 \%$ é explicado pela variância total. Além disso, é possível aferir que a maior parte da variância é explicada pelo fator 1, com 23,017\%, seguido do fator 2 com 10,401\%, seguida dos fatores 3, 4 e 5 que possuem variância próxima a $6 \%$ e dos fatores 6 e 7, com variância próxima a 5\%. A seguir foi feita a etapa $A$ lpha de Cronbach, que com sua variação entre 0 e 1 descarta como aceito o intervalo entre 0,6 e 0,07 . Na tabela 6 é possível notar que mais da metade dos fatores se encontram no intervalo de exclusão, portanto são eliminados os fatores 4,5, 6 e 7 por terem valores próximos a 0,4 . 
Tabela 6 - Alpha de Cronbach de todos os fatores

\begin{tabular}{|l|l|l|l|}
\hline Fator & Alpha de Cronbach & Número de Variáveis & Status \\
\hline 1 & .750 & 3 & Mantido \\
\hline 2 & .662 & 4 & Mantido \\
\hline 3 & .686 & 4 & Mantido \\
\hline 4 & .449 & 3 & Eliminado \\
\hline 5 & .373 & 2 & Eliminado \\
\hline 6 & .476 & 2 & Eliminado \\
\hline 7 & $.463 \quad$ & Eliminado \\
\hline
\end{tabular}

O primeiro fator é composto pelas variáveis: 21, 20 e 22. O fator 1 apresenta índice de confiabilidade 0,75, o que indicia uma consistência interna boa (Pestana \& Gageiro, 2005). O segundo fator é formado pelas variáveis: 2, 3, 6, e 23. O valor de Alpha de Cronbach para esse fator é 0,662 o que denota uma consistência interna boa (Pestana \& Gageiro, 2005).

O terceiro fator é o último a ser mantido, com valor de 0,686 , formado pelas variáveis: 11, 16, 10, 8. O quarto fator é formado por 3 variáveis: 17, 14 e 7. Essas variáveis geram um Alpha de Crombach de 0,449 e indica um valor insatisfatório de consistência interna, o que causa sua eliminação na análise. Assim como o quarto fator, o quinto fator possui valor abaixo do esperado, 0,373 , e foi eliminado na análise. Suas variáveis são duas: 19 e 15 . O penúltimo fator é o sexto, com valor de análise 0,476 , e também foi eliminado com as variáveis: 12 e 13 . O sétimo fator é composto por duas variáveis: 4 e 5 . Seu valor para Alpha de Crombach é de 0,463, o que justifica sua eliminação.

Após a análise dos fatores por Alpha de Cronbach foi realizado o procedimento de Matriz Rotacionada de Fatores pelo método de rotação Equamax e extração dos fatores "Alpha Factoring". Esse método considera as variáveis envolvidas na análise como uma amostra do universo potencial das variáveis, maximizando os resultados de confiabilidade (SPPS, 2004). A proposta original era a solução por 7 fatores, que explicam a solução com $62,865 \%$ pela melhor aderência ao modelo e por oferecer explicação dos fatores. Porém, após o uso do Alpha de Cronbach, 4 dos 7 fatores foram eliminados por apresentarem baixos fatores de consistência interna. Assim, a solução final ficou com 3 fatores que foram nomeados de acordo com a relação que possuíam com o referencial teórico. A Matrix Rotacionada de Fatores foi apresentada na Tabela 7. 
Tabela 7 - Tabela de fatores rotacionados por quartimax e extração Alpha Factoring.

\begin{tabular}{|c|c|c|c|c|}
\hline \multicolumn{5}{|c|}{ Rotated Component Matrixa } \\
\hline & & \multicolumn{3}{|c|}{ Component } \\
\hline & & 1 & 2 & 3 \\
\hline \multirow{3}{*}{ 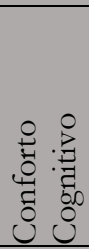 } & $\begin{array}{l}\text { 21) Eu estou em restaurante que conheço e vejo muitas pessoas consumindo um mesmo prato } \\
\text { que já vi, mas nunca experimentei. Isso me deixa confortável em experimentar esse produto. }\end{array}$ & .833 & & \\
\hline & $\begin{array}{l}\text { 20) Eu estou em um restaurante desconhecido e vejo muitas pessoas consumindo o mesmo } \\
\text { prato. Eu, então, me sinto confortável para experimentar aquele prato que nunca comi. }\end{array}$ & .783 & & \\
\hline & $\begin{array}{l}\text { 22) Estou de férias na praia com um grupo de amigos em um ambiente relaxante. Vamos a uma } \\
\text { sorveteria, tendo a experimentar um sabor que nunca experimentei pois todos estão pedindo. }\end{array}$ & .538 & & \\
\hline \multirow{4}{*}{ 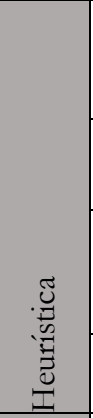 } & $\begin{array}{l}\text { 2) Estou viajando a trabalho no interior e vou a um restaurante desconhecido e possuo pouco } \\
\text { tempo para almoçar. Neste caso eu observaria qual prato a maioria das pessoas ao redor } \\
\text { escolhem antes de fazer meu pedido. }\end{array}$ & & .691 & \\
\hline & $\begin{array}{l}\text { 3) Vou a uma pizzaria com muitas pessoas com gostos diferentes. Nesta situação, tendo a olhar } \\
\text { os sabores mais consumidos naquele local para fazer o meu pedido. }\end{array}$ & & .683 & \\
\hline & $\begin{array}{l}\text { 6) Eu e meu namorado(a) fomos a uma doceria que está muito cheia, apesar de eu gostar mais } \\
\text { de quindim, o comportamento médio das pessoas demonstra que o doce mais vendido é o } \\
\text { churros. Dessa forma, tendo a escolher o churros. }\end{array}$ & & .650 & \\
\hline & $\begin{array}{l}\text { 23) Eu estou em um restaurante desconhecido e em geral peço o mesmo prato que as outras } \\
\text { pessoas estão pedindo porque isso reduz a minha insegurança. }\end{array}$ & & .576 & \\
\hline \multirow{5}{*}{ 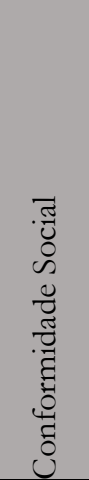 } & $\begin{array}{l}\text { 11) Estou em um jantar onde todos estão comendo Escargot. Quero experimentar aquela } \\
\text { iguaria, mas não sei como usar o utensílio para comê-la. Eu tendo a olhar para os comensais ao } \\
\text { lado para aprender a comer como eles comem. }\end{array}$ & & & .728 \\
\hline & $\begin{array}{l}\text { 16) Vou a restaurante de um renomado Chef pela primeira vez. Caso ele me indique um prato } \\
\text { específico que é muito vendido e que eu nunca experimentei, sigo a sugestão dele. }\end{array}$ & & & .679 \\
\hline & $\begin{array}{l}\text { 10) Estou em um restaurante temático de comida eslava. Não conheço os pratos e assim } \\
\text { pergunto ao garçom sobre o prato mais vendido antes de fazer a melhor opção. }\end{array}$ & & & .656 \\
\hline & $\begin{array}{l}\text { 8) Estou em uma praia na Tailândia, a qual visito pela primeira vez, e percebi que ali é muito } \\
\text { comum consumir um prato específico na hora do almoço. Eu tendo a pedir o prato. }\end{array}$ & & & .555 \\
\hline & $\begin{array}{l}\text { 17) Mesmo não tendo uma dieta rica em açúcar, ao viajar para a Disney eu tendo a } \\
\text { experimentar alguns doces que são vendidos nos parques pois me sinto desinibido para comer } \\
\text { esse produto sem peso na consciência. }\end{array}$ & & & .419 \\
\hline
\end{tabular}

Extraction Method: Principal Component Analysis.

Rotation Method: V arimax with Kaiser Normalization.

Rotation converged in 9 iterations.

Fonte: Pesquisa (2017)

O primeiro fator foi nomeado como Conforto Cognitivo. Indica que as variáveis agrupadas trazem questões de familiaridade com a exposição a objetos ou situações. Esse tipo de questão favorece o consumo de artigos que de alguma forma se encaixam em percepções já estabelecidas e permite que os consumidores se sentam confortáveis com certa escolha, em nosso caso em particular, escolha de alimentos em seu processo de compra. Como já destacado por Dolan e Kahneman (2008) o conforto cognitivo é uma das características de (S1) - parte intuitiva que opera automaticamente em processos decisórios, que podem conduzir a sensação tranquilizadora e de familiaridade, visto que pelo fato de operar em percepções automáticas permitem um menor esforço em seu processo, ou seja, nota-se que nas questões que quando outras pessoas possuem determinados comportamentos, tende-se a replicá-los para que possa, teoricamente, evocar sentimentos tranquilizadores em relação a decisão de compra. Pode-se tomar decisões pelo Sistema $1 \mathrm{sem}$, aparentemente, fazer uso do Sistema 2.

Já em relação a familiaridade, conforme já destacado, ocorre em situações nas quais tem-se a hipótese de ativação/desativação, destacado anteriormente de FARM (Jacoby \& Kelley, 1990; Schwarz \& Clore, 1996; Smith, 1994). É o entendimento que se um estímulo se adequar a uma representação mnésica pode tornar o seu processamento fluente, familiar e, consequentemente, permite uma decisão segura, uma adaptação a um estímulo já conhecido. Entende-se desta forma que os estímulos captados no momento 
de decisão de compra, por ser algo que já possuí uma representação na memória destes consumidores, permite o entendimento de certa segurança em sua decisão, como acompanha-se nas questões de consumo descritas no modelo proposto. Permite, em tese, uma melhor decisão de compra com o ato de replicar o comportamento de outros agentes persentes em um local de consumo, visto que, ativa percepções já concebidas na memória destes consumidores, levando, desta forma, a percepção de decisões mais seguras pelo fato de outras pessoas no ambiente ratificaram ideias pré-concebidas.

Já o segundo fator foi denominado Heurística por empregar variáveis em que o respondente ignora parte da informação com objetivo de tornar a escolha de alguma forma mais fácil ou rápida. É um procedimento que ajuda a encontrar respostas adequadas, ainda que em determinadas situações possam ser imperfeitas (Luppe \& De Angelo, 2010). As variáveis propostas no modelo demonstram que, conforme teoria apresentada na investigação, quando as decisões são tomadas de forma irracional ou não consciente, é comum que existam estratégias que negligencie informações para tornar a escolha fácil, rápida e prática, como descrito por Gigerenzer (2000) com o nome de Heurísticas Rápidas e Frugais, que empregam tempo, conhecimento e computação mínimos para fazer escolhas. Assim, os indivíduos ignoram determinadas informações para reduzir a sobrecarga de informações e assim reduzindo a tensão em momentos de decisão.

Essas questões favorecem o consumo de produtos por insegurança do consumidor em sustentar outra decisão, como pode-se notar nas assertivas 2, 3, 6 e 23, nas quais, nota-se que os entrevistados procuram informações no ambiente de compra para as suas decisões de consumo, não de uma forma lógica, mas em muitas situações para que possam decidir de forma rápida e fácil. Assim, replicam o comportamento de outras pessoas no contexto no qual se encontram. Buscam informações de outros consumidores para facilitar as suas decisões e, se comportam em seu processo decisório de acordo com outras pessoas presentes no ponto de venda e de acordo com a maioria dos clientes pelos quais pode observar neste momento.

A conformidade social foi usada para definir o conjunto de questões que interiorizam regras e sua partilha com os outros, de forma que um grupo tende a agir em conformidade com as expectativas de outros integrantes de grupos sociais no qual pertence, ou que gostaria de pertencer, neste último caso é evidenciado a importância de imitar o comportamento de outros integrantes do grupo social. Essas questões favorecem consumo em locais onde a sociabilidade com as pessoas ao redor é um fator importante na hora da tomada de decisão.

Infere-se no estudo que os consumidores tendem a replicar o comportamento de outras pessoas para que possam se adequar as regras, em nosso caso em particular, regras de consumo de alimentos em restaurantes, para que possa se adequar a um determinado grupo. Fatores como Desindividualização, Reputação, e Aprendizado (Jesus, 2013) podem ser extraídos desta parte do modelo, visto que os consumidores se desvinculam de seus fatores pessoais para uma maior adequação ao grupo, ou seja, replicando comportamentos estabelecidos, bem como para manter certa reputação e aprende comportamentos com o ato de se comportar de forma similar ao grupo.

Nota-se, conforme analise apresentada, que o modelo proposto para identificar o comportamento de manda no setor de alimentos e bebidas (tabela 7), com as devidas correções avalizadas estatisticamente, mostra-se aplicável para entender esse importante fenômeno presente no momento de decisão de compra dos consumidores. Cabe, ainda destacar, a importância de compreender esse comportamento, que ao que tudo indica, possuí sua relevância, tanto como os estudos de análise sensorial e ambiência que são importantes para a compreensão do setor.

\section{Considerações finais}

A busca por entender o processo de decisão de compra dos consumidores, toma várias roupagens, ou formas distintas de compreensão. Desde os modelos mais convencionais como aqueles normalmente 
usados na literatura mercadológica oriundos da economia clássica, bem como aqueles que partem do pressuposto que outros fatores, como o contexto, ou o melhor entendimento das funções cerebrais auxiliam um entendimento mais aprofundado no processo de decisão de compra.

Essa busca pelo melhor entendimento desses fatores foi a linha condutora desse trabalho. Entender o comportamento manda, ou em sua língua original, o Herd Behavior, no qual é assumido como a tendência que as pessoas possuem em seguir outras, em nosso caso particular, outros comportamentos para a redução da incerteza em um processo de decisão de compra no setor de A\&B. Esse comportamento já foi abordado em vários estudos, como por exemplo, para identificar tais comportamentos nos mercados financeiros, o que nos levou a questionar se esse comportamento não estaria, também, presente no setor de alimentos e bebidas.

Os resultados obtidos por meio da revisão bibliográfica, como os estudos de conformidade social de Asch (1956), economia de energia de Giggerenzer e Todd (2000), e de conforto cognitivo de Kahneman e Tversky (1974), permitiram perceber as motivações que cada grupo ou individuo possuí para seguir outros (ter os mesmos comportamentos) em seu processo de decisão de compra, sendo adaptados ao mercado de A\&B.

É importante ressaltar que o comportamento manada, ao que as pesquisas demonstraram, parece mais presente em momento de incerteza, e quando existem limitações de tempo e de processamento de informações no momento de definir qual a melhor opção a ser tomada em uma determinada situação. A partir desse contexto apresentado, os autores se propuseram a uma revisão bibliográfica, criar um mapa teórico com fatores responsáveis pelo comportamento de manada no setor de A\&B, e consequentemente a criação de uma escala que pudesse ser posteriormente replicada em situações correlatas. Essa escala foi composta dos seguintes elementos: experiências repetidas. Bom humor, heurística, crowdness, redução da incerteza, aprendizado, reputação e desindividualização.

A pesquisa realizada encontrou, na literatura nacional e estrangeira, poucos trabalhos que tratem do comportamento de manada relacionado ao setor de $A \& B$. Cabe destaque que não foi encontrada nenhuma escala para medir esse fenômeno, o que nos levou a sua criação. Tal cenário nos conduziu a questão central dessa pesquisa: Como pode-se medir o comportamento de manda dentro de estabelecimento de alimentação? . Pode-se afirmar que, como destacado no processo de análise estatística dos dados, podese, sim, com um método estruturado, compreender com maior precisão a presença desses fenômenos em estabelecimento de alimentação.

Em relação ao objetivo geral dessa investigação foi estabelecido a construção e validação de uma escala que pudesse medir o comportamento de manada dentro de estabelecimentos de alimentação, mais particularmente restaurantes, lanchonetes, confeitarias, dentre outros. Pode-se assegurar que o mesmo foi cumprido. O modelo, estaticamente, mostrou-se viável para tal objetivo.

Já, com relação aos objetivos específicos: a) compreender as principais teorias relacionadas ao estudo do comportamento do consumidor, foi atingido, visto que, para a construção da escala, conduziu os autores a pesquisa de uma vasta literatura existente sobre o tema; b) inserir o entendimento do comportamento de manada dentro das teorias comportamentais de estudo do consumidor. Também foi atingido no momento que os autores conseguiram estabelecer o comportamento manda dentro do escopo do estudo de comportamento do consumidor; c) tratar estatisticamente os dados presentes na literatura para o consequente desenvolvimento e validação de uma escala que possa ser replicada em estudos posteriores. Também se obteve sucesso nessa empreitada, visto que, o modelo poderá ser usado para outros trabalhos e assim contribuir para o estudo da área.

Acredita-se que a pesquisa possa contribuir para novos estudos no setor de $A \& B$, bem como instigar a discussão em relação ao entendimento dos processos decisórios. Em relação as teorias de comportamento do consumidor, destaca-se que à medida que os mercados se tornam mais 
competitivos, entender o comportamento dos clientes é de fundamental importância tanto para gestores como para acadêmicos. Neste sentido vários campos de estudo dos clientes estão se destacando, como a Economia Comportamental, Psicologia Social e outras áreas que estudam os comportamentos não conscientes dos clientes. Diante deste cenário este estudo pode contribuir com estas novas vertentes do mercado, bem como subsidiar novas pesquisas na área. Para o campo gerencial, espera-se que esta investigação contribua para que as empresas do setor possam ter uma melhor perspectiva dos fenômenos relacionados aos processos decisórios, entender de forma contundente o comportamento dos clientes, e possibilitar novas vertentes em suas estratégias, tanto de Marketing, como empresariais.

\section{Referências}

ABIA - Associação Brasileira da Indústria de Alimentos.(2017). Disponível em:

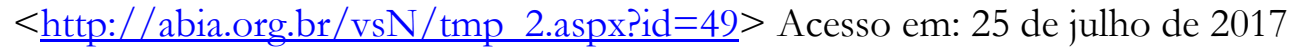

ABRASEL - Associação Brasileira de Bares e Restaurantes. (2015). Pesquisa de Conjuntura Econômica do Setor de Alimentação Fora do Lar - 2015. Disponível em: <http://pe.abrasel.com.br/noticias/70723102015-conjuntura-economica-do-setor-de-alimentacao-fora-do-lar. $\% 20$ Acesso $\% 20 \mathrm{em} \% 2020-06$ 2016> Acesso em: 26 de julho de 2017

Araújo, R. (2009). Experimentos em Psicologia - A unanimidade burra de Solomon Asch. Não Posso Evitar.....Disponível em:< http://www.naopossoevitar.com.br/2009/06/experimentos-em-psicologiaa-unanimida-de-burra-de-solomon-asch.html>. Acesso em 24 set. 2017.

Broadbent, D. E. (1958). Perception and communication. Londres: Pergamon Press.

Bruner, J. S. (1957). Going beyond the information given. New York: Norton.

Buccino, G. et al. (2004). The mirror neuron system and action recognition. Brain and Language, v. 89, p. 370-376.

Carvalho, F. R. D. C. (2013). Análise Fatorial. Dissertação (Mestrado em Matemática) - Faculdade de Ciências e Tecnologias da Universidade de Coimbra. Disponível em:<https://estudogeral.sib.uc.pt/bitstream/10316/33696/1/Analise\%20fatorial_FranciscoCarvalho. pdf $>$. Acesso em 16 dez. 2017.

Cobra, M. (1992). Administração de Marketing. São Paulo: Atlas.

Daunt, K. L. \& Greer, D. A. (2015). Unpacking the perceived opportunity to misbehave: the influence of spatio-temporal and social dimensions on consumer misbehavior. European Journal of Marketing, Bradford, v. 49, n. 9-10, p. 1505-1526.

Dobbs, D. (2006). Reflexos reveladores. Mente \& Cérebro, v. 161, p. 46-51.

Dolan, P. \& Kahneman, D. (2008). Interpretations of utility and their implications for the valuation of health. The Economic Journal, v. 118, n. 525, p. 215-234.

Engel, J. F., Blackwell, R. D. \& Miniard, P. W. (2005). O comportamento do consumidor. São Paulo: Pioneira Thomson Learning.

Festinger, L., Pepitone, A. \& Newcomb, T. (1952). Some consequences of deindividuation in a group. Journal of Social Psychology, v. 47, p. 382-389.

Fullerton, R. A. \& Punj, G. (1993). Choosing to misbehave: a structural model of aberrante consumer behavior. Advances in Consumer Research, Urbana, v. 20, n. 1, p. 570-574.

Garcia-Marques, T. (2003). A regulação da activação de diferentes modos de processamento da informação: O papel do "sentimento de familiaridade". Análise Psicológica, Lisboa, v. 21, n. 3, p. 267-285. Disponível em:<http://publicacoes.ispa.pt/publicacoes/index.php/ap/article/view/11/pdf>. Acesso 
em 16 set. 2017.

Gigerenzer, G. \& Todd, P. M. (2000). Simple heuristics that make us smart. $A B C$ Research, Oxford University Press.

Gil, A. C. (1999). Métodos e técnicas de pesquisa social. 5. ed. São Paulo: Atlas.

Gilovich, T., Griffin, D. \& Kahneman, D. (2002). Heuristics and Biases: The psychology of intuitive judgment. New York: Cambridge University Press.

Harris, L. C. \& Reynolds, K. L. (2003). The Consequences of Dysfunctional Customer Behavior. Journal of Service Research, v.6, n. 2, p. 144-161.

Higgins, E. T. (1996). Knowledge activation: accessibility, applicability, and salience. Social psychology Handbook of basic principles. New York: Guilford, p. 133-168.

Jacoby, L. \& Kelley, C. (1990). An episodic view of motivation: unconscious influences of memory. Handbook of Motivation and Cognition. New York: Guilford Press, v. 2, pp. 451-481.

Jesus, J. G. (2013). Psicologia das massas: contexto e desafios brasileiros. Psicologia \& Sociedade, v. 25, n. 3, p. 493-503. Disponível em: $<\mathrm{http} / /$ www.scielo.br/scielo.php?script=sci_arttext\&pid=S0102$71822013000300003 \& \operatorname{lng}=$ en\&nrm=iso $>$. Acesso em 24 set. 2017.

Kahneman, D. (2011). Thinking, fast and slow. London: Allen Lane, 2011.

Karsaklian, E. (2004). Comportamento do Consumidor. São Paulo: Atlas, 2004.

Kimura, H., Basso, L. F. C. \& Krauter, E. (2006). Paradoxos em finanças: teoria moderna versus finanças comportamentais. Revista de Administração de Empresas, v. 46, n.1, p. 41-58. Disponível em: $<$ http:/ /www.scielo.br/scielo.php?script=sci_arttext\&pid=S003475902006000100005\&lng=en\&nrm= iso $>$. Acesso em 24 set. 2017.

Kotler, P. \& Keller, K. L. (2012). Administração de Marketing. 14 ed. São Paulo: Ed. Pearson Education.

Libai, B., et al. (2010). Customer-to-Customer Interactions: Broadening the Scope of Word of Mouth Research. Journal of Service Research, v. 13, n. 3, p. 267-282.

Limeira, T. M. V. (2009). Comportamento do consumidor brasileiro. São Paulo: Saraiva.

Luppe, M. R. \& Felisoni de Angelo, C. (2010). As decisões de consumo e a heurística da ancoragem: uma análise da racionalidade do processo de escolha. Revista de Administração Mackeñ̨ie, São Paulo, v. 11, n. 6, p. 81-106. Disponível em:<http://www.redalyc.org/html/1954/195416630006/>. Acesso em: 16 set. 2017.

Malhotra, N. (2006). Pesquisa de marketing: uma orientação aplicada. 4. ed. Porto Alegre: Bookman.

Miller, R.P. \& Brehm, S. (2006).Intimate Relationships. New York: McGraw-Hill.

Monahan J. L., Murphy S. T. \& Zajonc, R. B. (2000). Subliminal mere exposure: specific, general, and diffuse effects. Psychological Science, v. 11, n. 6, p. 462-466.

Moore, R., Moore, M. L. \& Capella, M. (2005). The impact of customer-to-customer interactions in a high personal contact service setting. Journal of Services Marketing, v. 19, n. 7, p. 482-49.

Mowen, J. C. \& Minor, M. S. (2003). Comportamento do consumidor. São. Paulo: Pearson Prentice Hall.

Nalini, L. E. E. G., DE Melo Cardoso, M. \& Cunha, S. R. (2013).Comportamento do Consumidor: uma introdução ao Behavioral Perspective Model (BPM). Fragmentos de Cultura, Goiânia, v. 23, n. 4, p. 489-505.Disponível

em:<http://revistas.pucgoias.edu.br/index.php/fragmentos/article/view/2976/1821>. Acesso em 16 set. 2017. 
Ng., I. C. L. \& Tseng, L. (2008).Learning to be sociable: the evolution of homo economicus. American Journal of Economics and Sociology, v. 67, n. 2, p. 265-286. Disponível em:<https://www.researchgate.net/publication/4750978_Evolution_of_Homo_Economicus>.

Acesso em 16 set. 2017.

Oliveira, S. L. I.. (2007). Desmistificando o Marketing. São Paulo: Novatec.

Pestana, M. H. \& Gageiro, J. N. (2005). Análise de Dados para Ciências Sociais. A Complementaridade do SPSS. Lisboa: Sílabo.

Rizzolatti, G. \& Arbib, M. A. (1998). Language within our grasp. Trends Neuroscience, v. 21, p. 188-194, 1998.

Rizzolatti, G. \& Arbib, M. A. (1996). Premotor cortex and the recognition of motor actions. Cognitive Brain Research, v. 3, p. 131-141.

Rizzolatti, G., Arbib, M. A. Craighero, L. (2004). The mirror-neuron system. Annual Review of Neuroscience, v. 27, p; 169-192.

Rocha, M. (Org.). (2015).Marketing Estratégico. São Paulo: Saraiva.

Samara, B. S. \& Morsch, M. A. (2005). Comportamento do consumidor. conceitos e casos. São Paulo: Pretince Hall.

Sanches, M. V. (2013).Comportamento de manada em direção ao indice de mercado: evidências no mercado brasileiro de ações. Dissertação (Mestrado em Administração de Empresas) - Universidade de São Paulo, São Paulo, 2013.

Schwarz, N. \& Clore, G. L. (1996).Feelings and phenomenal experiences. Social psychology: handbook of basic principles. New York: Guilford, p. 433-465.

Sherman, S. J. \&Corty, E.. (1984).Cognitive heuristics. In: WYER, R. S.; SRULL, T. K. (Eds.), Handbook of social cognition, Hillsdale, v. 1, pp. 189-286.

Sheth, J., Mittal, B. \& Newman, B. N. (2001).Comportamento do cliente: indo além do comportamento do consumidor. 1 ed. São Paulo: Atlas.

Simon, H. A. (1957). Models of Man, Social and Rational: Mathematical Essays on Rational Human Behavior in a Social Setting. New York: John Wiley and Sons.

Smith, E. R. (1994).Procedural knowledge and processing strategies in social cognition. Handbook of social cognition, 2 ed., v. 1, p. 99-151.

Smith, E. R. \& Zarate, M. A. (1992).Exemplar-based model of social judgment. Psychological Review, v. 99, n. 1, p. 3-21.

Solomon, M. R. (2009).O Comportamento do consumidor. Porto Alegre: Artmed.

Tse, A. C. B., Sin, L. \& Yim, F. H.K. (2002). How a crowded restaurant affects consumers' attribution behavior. International Journal of Hospitality Management. Department of Marketing, The Chinese University of Hong Kong, Shatin, Hong Kong, v. 21, 4 ed., p. 449-454. Disponível em:<http://www.sciencedirect.com/science/article/pii/S027843190200035X>. Acesso em 19 dez. 2017.

Tversky, A.\& Kahneman, D. (1974). Judgment under uncertainty: Heuristics and biases. Science, 185, p. 1124-1130, 1974.

Tversky, A.\& Kahneman, D. (1979). Prospect theory: an analysis of decision under risk. Econometrica, v. 47,n.2,p.263-291. Disponível em: $<$ https://www.princeton.edu/ kahneman/docs/Publications/prospect_theory.pdf $>$. Acesso em 16 set. 2017. 
Tversky, A.\& Kahneman, D. (1981).The framing of decisions and psychology of choice. Science - New Series, v. 211, n. 4481, pp. 453-458. Disponível em:< http://www.krigolson.com/uploads/4/3/8/4/43848243/tversky_1981.pdf>. Acesso em 16 set. 2017.

Tversky, A.\& Kahneman, D. (1992).The psychology of preferences. Scientific American, v. 146, p. 160173.

Varian, H. R. (2003). Microeconomia: princípios básicos - uma abordagem moderna. Rio de Janeiro: Editora Campus, Elsevier.

Wilkes, R. E. (1978).Fraudulent behavior by consumers. Journal of Marketing, Chicago, v. 42, n. 4, p. 67 75.

Zimbardo, P. G. (1969).The human choice: Individuation, reason, and order versus deindividuation, impulse, and chaos. Lincoln: University of Nebraska, p. 237-307. 